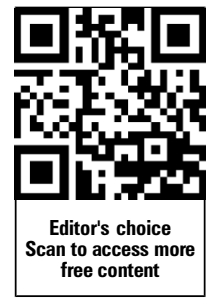

- Additional material is published online only. To view please visit the journal online (http://dx.doi.org/10.1136/ thoraxjnl-2012-202915)

For numbered affiliations see end of article.

\section{Correspondence to} Maggie Patricia Mcllwaine, Division of Paediatric Respirology and Department of Physiotherapy, Cystic Fibrosis Clinic, BC Children's Hospital and University of British Columbia, Room K3-202, BC Children's Hospital, 4480 Oak Street, Vancouver, BC V6H 3V4, Canada; mmcilwaine@cw.bc.ca

Received 23 October 2012 Revised 12 January 2013 Accepted 16 January 2013 Published Online First 13 February 2013

\title{
Long-term multicentre randomised controlled study of high frequency chest wall oscillation versus positive expiratory pressure mask in cystic fibrosis
}

\author{
Maggie Patricia Mcllwaine, ${ }^{1}$ Nancy Alarie, ${ }^{2}$ George F Davidson, ${ }^{3}$ Larry C Lands, ${ }^{4}$ \\ Felix Ratjen, ${ }^{5}$ Ruth Milner, ${ }^{6}$ Blythe Owen, ${ }^{7}$ Jennifer L Agnew ${ }^{8}$
}

\section{ABSTRACT \\ Background Positive expiratory pressure (PEP) is the} most commonly used method of airway clearance (AC) in Canada for patients with cystic fibrosis (CF) whereas, in some countries, high frequency chest wall oscillation (HFCWO) is the preferred form of AC. There have been no long-term studies comparing the efficacy of HFCWO and PEP in the CF population.

Objectives To determine the long-term efficacy of HFCWO compared with PEP mask therapy in the treatment of CF as measured by the number of pulmonary exacerbations (PEs).

Methods A randomised controlled study was performed in 12 CF centres in Canada. After a 2-month washout period, subjects were randomised to perform either HFCWO or PEP mask therapy for 1 year.

Results 107 subjects were enrolled in the study; 51 were randomised to PEP and 56 to HFCWO. There were 19 dropouts within the study period, of which 16 occurred prior to or at the time of randomisation. There were significant differences between the groups in the mean number of PEs (1.14 for PEP vs 2.0 for HFCWO) and time to first PE (220 days for PEP vs 115 days for HFCWO, $p=0.02)$. There was no significant difference in lung function, health-related quality of life scores or patient satisfaction scores between the two groups. PEP mask therapy required a shorter treatment time.

Conclusions The results of this study favour PEP and do not support the use of HFCWO as the primary form of $A C$ in patients with $C F$.

Clinical Trial Registration number NCT00817180.

\section{INTRODUCTION}

Cystic fibrosis (CF) is a lethal genetic disease caused by abnormalities in cystic fibrosis transmembrane conductance regulator protein function. Depletion of airway surface liquid, dehydrated mucus, chronic inflammation and infection contribute to accumulation of secretions and progressive airway damage. ${ }^{12}$ Promoting airway clearance (AC) using mucolytics together with airway clearance techniques (ACTs) form the basis for pulmonary therapy in CF care. ${ }^{3}$ Guidelines from the British Thoracic Society support with level $1+$ evidence the teaching of an ACT to patients with CF to increase mucus transport in the short term (grade A). ${ }^{4}$

The International Physiotherapy Group for Cystic Fibrosis (IPG/CF) has adopted a number of ACTs which are supported by randomised controlled

\section{Key messages}

What is the key question?

- Is high frequency chest wall oscillation (HFCWO) as effective as positive expiratory pressure (PEP) in maintaining health in patients with cystic fibrosis as measured by the number of pulmonary exacerbations (PEs)?

What is the bottom line?

- The number of PEs was significantly higher in patients performing HFCWO compared with those performing PEP.

Why read on?

- This article explains the background, methodology and outcome of a long-term trial studying the effectiveness of HFCWO compared with PEP.

studies as acceptable methods of AC. ${ }^{5}$ These include the active cycle of breathing technique, positive expiratory pressure (PEP), oscillating PEP, autogenic drainage and postural drainage and percussion (PD\&P). A survey of Canadian CF centres in 2007 revealed that PEP was the ACT of choice for the majority of patients over the age of $7 .^{6}$ This was based on the results of comparative trials conducted in Canada, demonstrating equivalence or superiority of PEP therapy compared with PD\&P. ${ }^{78}$

In the late 1980s another ACT called high frequency chest wall oscillation (HFCWO) was developed. HFCWO involves the use of an inflatable vest/jacket that covers the chest and is attached to an air pulse-generating compressor which rapidly inflates and deflates the vest, producing oscillations to the chest wall of $5-25 \mathrm{~Hz}$. It is proposed that HFCWO enhances mucociliary transport by creating a cough-like expiratory flow bias that shears mucus from the airway walls by enhancing ciliary beat frequency ${ }^{9}$ and by altering the rheological properties of mucus. ${ }^{10}$ In a Cochrane review on oscillating devices for people with CF, the authors concluded that there was no clear evidence that oscillation was a more or less effective intervention overall than other forms of $\mathrm{AC}$ and that more adequately powered long-term randomised 
controlled trials were necessary. ${ }^{11}$ One other aspect when considering which ACT to use is cost. The cost of a PEP device with a mask ranges from $£ 40$ to $£ 60$ whereas the cost of a HFCWO device is approximately $£ 7000$. This places a huge economic burden on the family of a patient with CF.

At the onset of this study there were no published long-term randomised controlled studies comparing HFCWO with any other AC technique including PEP. The primary objective of the present study was to determine the efficacy of HFCWO compared with PEP in maintaining respiratory health in patients with CF over a period of 1 year as measured by the number of pulmonary exacerbations (PEs). Secondary outcome measures included time to first PE, changes in lung function between groups and over time and health-related quality of life questionnaires.

\section{METHODS}

\section{Study design}

This was a 1-year prospective multicentre randomised controlled trial of HFCWO versus PEP as ACTs in the treatment of children and adults with CF. As $73 \%$ of participants were performing PEP on enrollment and to avoid any potential bias from using PEP, we included a 2-month washout period between visit 1 and visit 2 . During this time participants performed an IPG/CF recommended $\mathrm{ACT}^{5}$ other than HFCWO or PEP. Subjects were randomised to perform either PEP or HFCWO, but were not informed which ACT they had been assigned until visit 2 which followed the washout period. At visit 2, participants were instructed in their assigned ACT and commenced the 1-year study period using this technique. Although participants were not blinded as to the arm of the study to which they were randomised, physicians and respiratory therapists performing the respiratory assessments and lung function tests, respectively, were unaware of the treatment assignment. Assessments were performed at 3-monthly intervals during the regular visits of the participants to the CF centre, with visit 2 occurring at the commencement of the 1-year study period and visit 6 occurring at the end of 12 months.

\section{Study participants}

Eligible participants were CF patients over the age of 6 years with a confirmed diagnosis of CF who were clinically stable and met the inclusion/exclusion criteria (see online supplement).

The study took place between October 2008 and April 2012 in 12 CF Canada accredited CF centres across Canada (eight paediatric and four adult centres). Enrollment was completed by December 2010. The study was approved by the research ethics boards at each centre and written informed written consent/assent was obtained from each participant or their parents as appropriate.

\section{Protocol}

The principal investigators and research coordinators from each participating CF centre met for a 2-day training session prior to commencing the study. Both PEP and HFCWO techniques were reviewed along with practical training. RespirTech (St Paul, Minnesota, USA) representatives provided the training for HFCWO and supplied pre-programmed devices for the study. The PEP masks and devices were supplied by Smith Medical (Norwell, Massachusetts, USA). Neither company was involved in the design of the study nor did they provide any remuneration for the study.

At visit 2, after the 2-month washout period, study participants were instructed to perform the ACT assigned twice daily for a period of 1 year. Participants who were normally prescribed once daily AC prior to enrollment in the study were permitted to continue this frequency during the study. A Data
Safety Monitoring Board (DSMB) was instituted as mandated by Good Clinical Practice Guidelines. The study was registered at Clinical Trials.gov (identifier NCT00817180).

\section{PEP mask technique}

PEP was performed using a TheraPEP system with a mask. Participants were instructed to perform 15 breaths through the PEP mask followed by 2-3 huffs. This was repeated for six cycles (for further details see online supplement).

\section{High frequency chest wall oscillation (HFCWO)}

The HFCWO device used in this study was the inCourage System (RespirTech) as the triangular wave form produced by this system is thought to increase airflow velocity more than other devices. ${ }^{12}$ For the purposes of this study, the $30 \mathrm{~min}$ preprogrammed ramped Quick Start Program was used. Six 5-min cycles were performed, with the participant performing 2-3 huffs between cycles (for further details see online supplement).

\section{Outcome measures}

The primary outcome measure was the number of PEs requiring the use of an oral, inhaled or intravenous antibiotic. This definition was the same as that used by Saiman et al in the azithromycin study, ${ }^{13}$ and was based on the Early Pseudomonas Infection Control (EPIC) study with the exception that the duration of symptoms must have been longer than 3 days instead of 5 days (see online supplement). ${ }^{14}$ When a subject was prescribed an antibiotic, the prescribing physician completed an antibiotic utilisation form which included the signs and symptoms on which the PE was based.

Secondary outcomes measures included time to first PE; number of courses of intravenous antibiotics; changes in lung function; and health-related quality of life questionnaires. Lung function was measured using standardised equipment according to the American Thoracic Society guidelines. ${ }^{15}$ The prebronchodilator forced vital capacity (FVC), forced expiratory volume in $1 \mathrm{~s}\left(\mathrm{FEV}_{1}\right)$ and forced expiratory flow between $25 \%$ and $75 \%$ of vital capacity $\left(\mathrm{FEF}_{25-75}\right)$ were reported as absolute change and as a change in percent predicted from baseline using the National Health and Nutrition Examination Survey (NHANES) III scales. ${ }^{16}$

Quality of life was evaluated using the Cystic Fibrosis Questionnaire V.2. ${ }^{17}{ }^{18}$ A satisfaction questionnaire using a visual analogue scale of 1-5 was used to evaluate differences in satisfaction between treatment modalities. This measured the comfort, independence and flexibility in performing the treatments.

The above assessments were performed at 3-monthly intervals. In addition, participants received a monthly telephone call from study coordinators to check on adverse events and to encourage good adherence. They also kept a daily diary reporting any adverse events and checking off when they had performed their daily AC.

\section{Statistics}

As there was no standardised definition for PEs in patients with CF, we based our preliminary sample size calculations on Fuchs' criteria as used in the hypertonic saline trial by Elkins et al. ${ }^{19}$ In that study the mean number of PEs per participant over a 1-year period in the control group was 2.74 compared with 1.37 in the treatment group (difference 1.42). Thus, we based our study size on the mean number of exacerbations in the control group being 2.80 per year. To be able to detect a difference of $50 \%$ between the PEP and HFCWO groups, we would require 70 participants in each group (SD estimated to be 2.89). This statistical calculation has a power of $80 \%$ and $\alpha=0.05$ to detect a change from the control group. We calculated we would need to enroll 170 participants (85 in each group), which would 
allow for a $10 \%$ dropout in each group. This was later modified (see Results section).

Participants were randomised into two groups by an independent statistician using a computer generated randomisation table. As we were studying both children and adults and as a positive Pseudomonas status has been associated with a greater decline in lung function, ${ }^{20}$ we matched the subjects for age, sex and Pseudomonas status. The statistician also attempted to block patients within each centre to control for any treatment differences between centres. Statistical analysis was performed using SPSS V.18 according to the intention-to-treat principle. The primary outcome of number of PEs was analysed using the Mann-Whitney non-parametric test. A cross-tabulation was also performed using the Pearson $\chi^{2}$ test for all categorical data. Time to first PE was analysed using Kaplan-Meier survival analysis including a log rank test. Multivariate analysis was used to analyse the lung function data with repeated measures of ANOVA used to compare within-group differences between visits and between interventions. Satisfaction questionnaires were also analysed using the Mann-Whitney non-parametric test. A p value of $<0.05$ was considered significant.

\section{RESULTS}

\section{Participants}

Study enrollment was stopped in December 2010 once 107 patients were enrolled after discussion with the DSMB. This decision was based on the following considerations: (1) failure to recruit the expected number of subjects in the proposed time frame; and (2) the initial statistical calculations were based on the Fuchs' criteria ${ }^{21}$ for PEs rather than the modified EPIC trial definition $^{14}$ that served as the predefined primary outcome measure in this study, so the initial sample size calculation was considered rather conservative. The DSMB performed an interim analysis in October 2011 after two-thirds of the participants had completed the study due to an imbalance in the reported incidence of serious adverse events for PEs between the two groups and proposed that the study be completed with the current sample size.

Fifty-one subjects were randomised to the PEP arm of the study and 56 to the HFCWO arm. Both groups were clinically
Table 1 Patient demographics and baseline characteristics

\begin{tabular}{|c|c|c|}
\hline & PEP & HFCWO \\
\hline Number of subjects & 51 & 56 \\
\hline Median age (years) & 12 (range 6-41) & 11 (range 6-47) \\
\hline Age $6-11$ years & 25 & 31 \\
\hline Age $12-17$ years & 18 & 14 \\
\hline Age $18-47$ years & 8 & 11 \\
\hline Female/male & $25 / 26$ & $25 / 31$ \\
\hline Pseudomonas positive/negative & $17 / 34$ & $19 / 37$ \\
\hline FVC percent predicted & $100.7 \pm 13.8$ & $94.3 \pm 14.8$ \\
\hline $\mathrm{FEV}_{1}$ percent predicted & $92.9 \pm 17.2$ & $85.8 \pm 18.0$ \\
\hline $\mathrm{FEF}_{25-75}$ percent predicted & $79.7 \pm 31.6$ & $73.8 \pm 32.5$ \\
\hline Body mass index & $18.43 \pm 3.37$ & $18.62 \pm 4.55$ \\
\hline Delta F508 homozygous & $47 \%$ & $43 \%$ \\
\hline Regular use of inhaled bronchodilator & $88 \%$ & $88 \%$ \\
\hline Regular use of hypertonic saline & $12 \%$ & $13 \%$ \\
\hline Regular use of rhDNase & $25 \%$ & $30 \%$ \\
\hline Regular use of inhaled steroids & $55 \%$ & $48 \%$ \\
\hline Regular use of an inhaled antibiotic & $24 \%$ & $20 \%$ \\
\hline Regular use of azithromycin & $19 \%$ & $14 \%$ \\
\hline $\begin{array}{l}\text { Number of patients performing ACT } \\
\text { once daily }\end{array}$ & 12 & 12 \\
\hline \multicolumn{3}{|c|}{$\begin{array}{l}\text { Data for body mass index, } \mathrm{FVC}, \mathrm{FEV}_{1} \text { and } \mathrm{FEF}_{25-75} \text { are represented as mean } \pm \mathrm{SD} \text {. } \\
\mathrm{ACT} \text {, airway clearance technique; } \mathrm{FEF}_{25-75} \text {, forced expiratory flow between } 25 \% \text { and } \\
75 \% \text { of vital capacity; } \mathrm{FEV} \text {, forced expiratory volume in } 1 \mathrm{~s} ; \mathrm{FVC} \text {, forced vital } \\
\text { capacity; } \mathrm{HFCWO} \text {, high frequency chest wall oscillation; } \mathrm{PEP} \text {, positive expiratory } \\
\text { pressure. }\end{array}$} \\
\hline
\end{tabular}

comparable at enrollment (table 1). At visit 2, when subjects were to commence their prescribed arm of the study, there were eight dropouts from each arm of the study. Thus, at visit 2, 43 participants commenced on the PEP arm and 48 on the HFCWO arm. The study results were analysed on the intention-to-treat premise based on these participants. Between visit 2 and visit 6 at the end of the study there was one further dropout in the PEP group and two in the HFCWO group. Thus, 42 subjects in the PEP arm and 46 in the HFCWO arm completed the study (figure 1).
Figure 1 Flow chart of enrollment. HFCWO, high frequency chest wall oscillation; PEP, positive expiratory pressure.

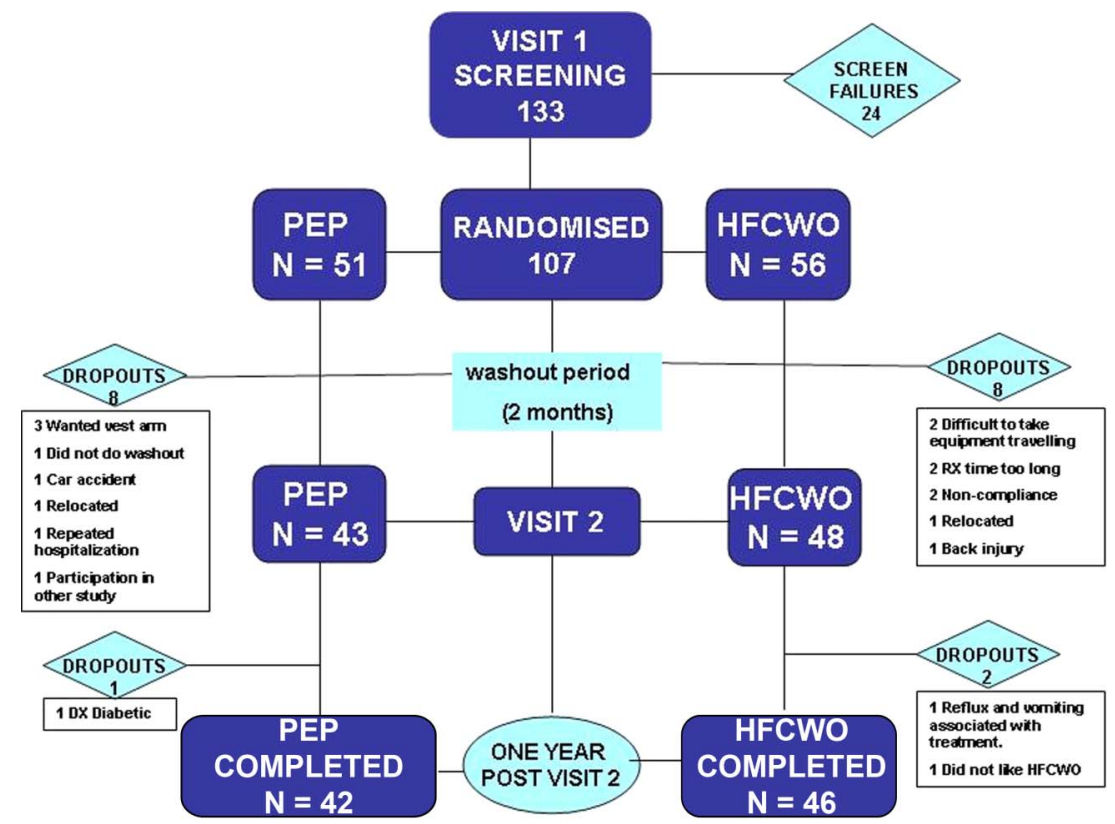


Table 2 Pulmonary exacerbations (PEs) reported for the two study groups

\begin{tabular}{|c|c|c|c|}
\hline & PEP & HFCWO & $p$ Value \\
\hline $\begin{array}{l}\text { Number of PEs requiring } \\
\text { antibiotics }\end{array}$ & $\begin{array}{l}49 \\
\text { Median1.00 } \\
(0.00,2.00)\end{array}$ & $\begin{array}{l}96 \\
\text { Median } 2.00 \\
(1.00,3.00)\end{array}$ & $0.007^{*}$ \\
\hline $\begin{array}{l}\text { Number of PEs requiring } \\
\text { intravenous antibiotics }\end{array}$ & $\begin{array}{l}6 \\
\text { Median } 0.00 \\
(0.00,0.00)\end{array}$ & $\begin{array}{l}19 \\
\text { Median } 0.00 \\
(0.00-1.00)\end{array}$ & 0.258 \\
\hline $\begin{array}{l}\text { Median length in days of } \\
\text { intravenous antibiotics per } \\
\text { treatment }\end{array}$ & $14.5(13,17)$ & $14(9.5,15)$ & 0.484 \\
\hline $\begin{array}{l}\text { Number of PEs requiring oral/ } \\
\text { inhaled antibiotics }\end{array}$ & $\begin{array}{l}43 \\
\text { Median } 1.00 \\
(0.00,2.00)\end{array}$ & $\begin{array}{l}77 \\
\text { Median } 2.00 \\
(1.00,3.00)\end{array}$ & $0.025^{*}$ \\
\hline
\end{tabular}

\section{Pulmonary exacerbations}

The overall number of PEs requiring oral, inhaled or intravenous antibiotics was 1.59 per participant and was evenly distributed throughout the $12 \mathrm{CF}$ centres. The number of PEs per participant in the PEP group was 1.14 compared with 2.0 in the HFCWO group ( $p=0.007$, table 2$)$. In addition, while the overall incidence was low, the number of PEs requiring intravenous antibiotics in the HFCWO group was more than three times the number in the PEP group. The time to first PE $\left(\mathrm{T}_{1 / 2}\right)$ in the PEP group was 220 days compared with 115 days in the HFCWO group $(p=0.02)$, as shown in the Kaplan-Meier plot in figure 2.

\section{Lung function}

As seen in figure 3, no significant difference in $\mathrm{FVC}, \mathrm{FEV}_{1}$ and $\mathrm{FEF}_{25-75}$ between the two groups was demonstrated. Absolute $\mathrm{FVC}$ and $\mathrm{FEV}_{1}$ increased significantly over the 1-year period (data not shown). FVC and $\mathrm{FEV}_{1}$ expressed as percent predicted

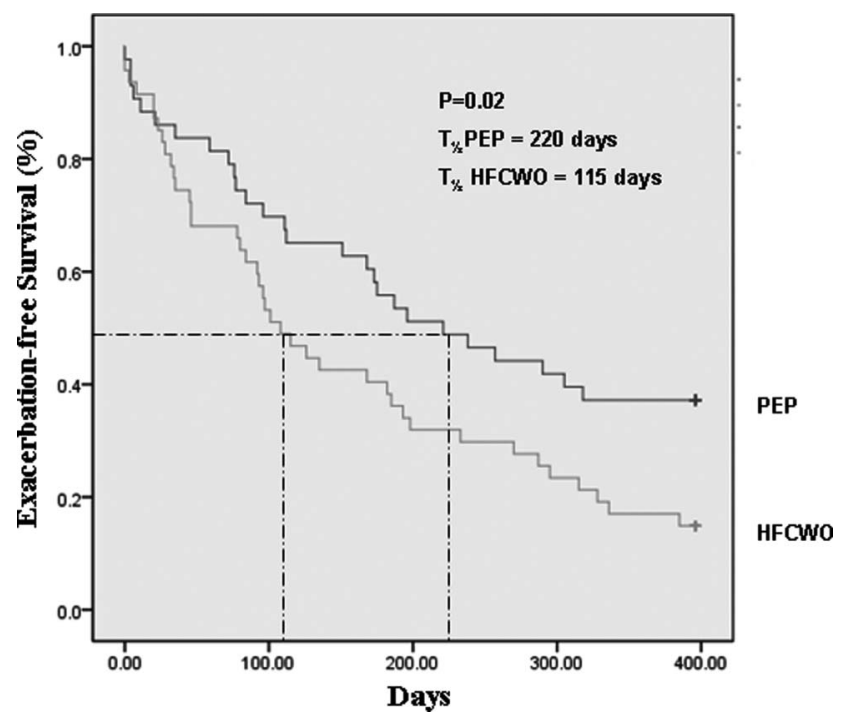

Figure 2 Kaplan-Meier plot of time to first pulmonary exacerbation (PE). $T_{1 / 2}$ refers to time when $50 \%$ of subjects have experienced their first PE. HFCWO, high frequency chest wall oscillation; PEP, positive expiratory pressure.
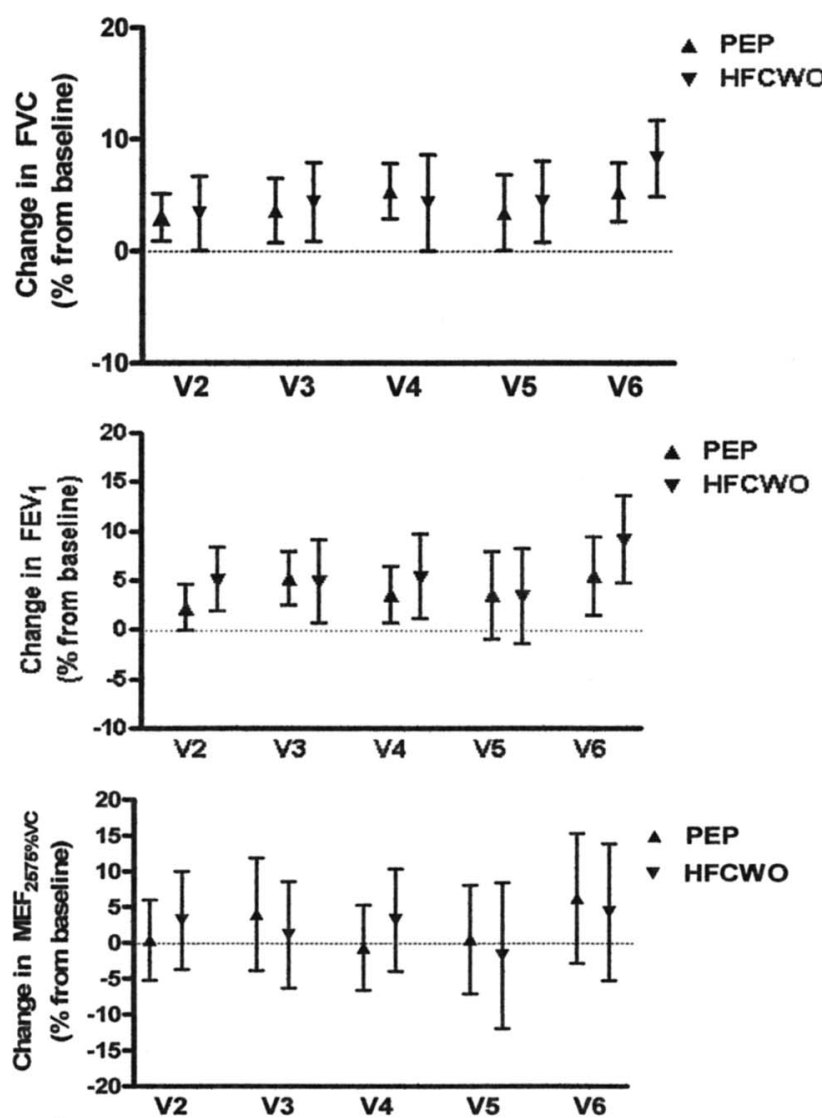

Figure 3 Changes in percent predicted for lung function. $\mathrm{FEV}_{1}$, forced expiratory volume in $1 \mathrm{~s}$; FVC, forced vital capacity; HFCWO, high frequency chest wall oscillation; $\mathrm{MEF}_{25-75}$, forced expiratory flow between $25 \%$ and $75 \%$ of vital capacity; PEP, positive expiratory pressure.

and analysed as change in percent predicted from baseline also increased significantly in both groups.

\section{Health-related quality of life}

The CF questionnaire data were analysed for change from baseline and are reported as mean \pm SD for the PEP and HFCWO groups, respectively, for the following domains: physical $(-0.84 \pm 3.3$ vs $-3.04 \pm 13.0)$, emotional $(0.48 \pm 11.9$ vs $-3.13 \pm 11.6)$, treatment burden $(-2.55 \pm 20.6$ vs $-3.60 \pm 18.2)$, respiratory $(2.98 \pm 17.0$ vs $0.19 \pm 17.1)$, digestion/weight $(-3.28 \pm 19.0$ vs $-2.12 \pm 25.1)$. The changes in the respiratory symptoms score in either group or between groups did not reach the minimally clinically important difference of 4 reported by Quittner et al. ${ }^{22}$

\section{Comfort, independence, flexibility, treatment time and} adherence

The visual analogue scores for comfort, independence and flexibility are shown in table 3 . No significant differences were observed for comfort and independence between PEP and HFCWO. Participants scored flexibility higher in the PEP group than in the HFCWO group, and this was related to the flexibility in where they could perform their ACT. Treatment time was significantly shorter in the PEP group. The recommended number of treatments per day was equivocal in both groups. Adherence, as reported through daily dairies, was high with participants missing only $6 \%$ of treatments in each group. 
Table 3 Treatment time, comfort, flexibility and adherence in the two study groups

\begin{tabular}{lllr}
\hline Self-reported measure & PEP & HFCWO & p Value \\
\hline Treatment time (min) & $20(15,20)$ & $30(20,35)$ & $<0.001$ \\
Comfort 1-5 & $5(4,5)$ & $5(4,5)$ & 0.474 \\
Independence 1-5 & $4(3,5)$ & $4(3,5)$ & 0.427 \\
Flexibility 1-5 & $5(4,5)$ & $4(3,5)$ & $<0.001$ \\
Mean number times per day & 1.75 & 1.76 & 0.962 \\
Mean number of misses per week & 0.5 & 0.5 & \\
\hline Data are presented as median (25\%, 75\% percentiles). & & \\
HFCW0, high frequency chest wall oscillation; PEP, positive expiratory pressure.
\end{tabular}

Data, presented as median and 25\%, 75\% percentiles except where stated otherwise, were measured on a Likert scale of 1-5, with 1 being the least comfortable, independent and flexible and 5 being the most comfortable, independent and flexible.

\section{Adverse events}

The total number of adverse events was not significantly different between the two groups (163 in the PEP vs 200 in the HFCWO group). However, there were significantly more adverse events related to the lower airways in the HFCWO group than in the PEP group (mean 2.46 vs $1.72, \mathrm{p}=0.023$ ). These included increased cough, chest infection, haemoptysis, decreased lung function and chest pain (for further details see online supplement and table 4).

\section{DISCUSSION}

This multicentre study is the first long-term randomised trial comparing HFCWO and PEP in the treatment of CF. It included 12 children and adult CF centres in Canada, so the results can be generalised across a broad CF population. The study was limited by the fact that the majority of participants were on PEP prior to the study, although attempts were made to limit any potential bias from this by having a washout period. In addition, although participants were matched for randomisation purposes, this did not take into account whether there were any differences between groups in the number of PEs in the year prior to the study. However, the results did show that the number of PEs in the HFCWO group was significantly higher than in the PEP group. This is an important finding as both the number of PEs and the

\section{Table 4 Adverse events}

\begin{tabular}{|c|c|c|c|}
\hline & PEP & HFCWO & Total \\
\hline $\mathrm{n}$ & 43 & 48 & 91 \\
\hline Total adverse events & 163 & 200 & 363 \\
\hline Median (lower-upper quartile) & $3(2-6)$ & $4(2-6)$ & $4(2-6)$ \\
\hline $\begin{array}{l}\text { Adverse events leading to study } \\
\text { device interruption }\end{array}$ & 7 & 10 & 17 \\
\hline $\begin{array}{l}\text { Adverse events leading to study } \\
\text { device discontinuation }\end{array}$ & 2 & $3^{*}$ & 5 \\
\hline $\begin{array}{l}\text { Serious adverse events (all } \\
\text { causes) (all resulted in } \\
\text { hospitalisation) }\end{array}$ & $\begin{array}{l}14 \\
\text { (6 patients) }\end{array}$ & $\begin{array}{l}27 \\
\text { (7 patients) }\end{array}$ & $\begin{array}{l}41 \\
\text { (13 patients) }\end{array}$ \\
\hline $\begin{array}{l}\text { Serious adverse events due to PE } \\
\text { (all resulted in hospitalisation) }\end{array}$ & $\begin{array}{l}6 \\
\text { (6 patients) }\end{array}$ & $\begin{array}{l}19 \\
\text { (14 patients }\end{array}$ & $\begin{array}{l}25 \\
\text { (20 patients) }\end{array}$ \\
\hline
\end{tabular}

${ }^{*}$ One adverse event led to study device discontinuation because it coincided with the end of the study for that subject.

HFCWO, high frequency chest wall oscillation; PE, pulmonary exacerbation;

$\mathrm{PEP}$, positive expiratory pressure. time to PEs have been associated with greater lung function decline and higher morbidity and mortality. ${ }^{23}$

Previous AC studies have used pulmonary function and sputum weight as primary outcome measures; however, the number of PEs and the time to first PE may provide a more sensitive measure that captures clinical response to treatment. ${ }^{19} \mathrm{AC}$ interventions may affect lung function decline, but studies that assess change in the rate of pulmonary function decline require a much larger sample size or longer duration of follow-up. ${ }^{23}$ A recent analysis suggested that $50 \%$ of lung function decline is explained by PEs, thus quantification of PEs may potentially serve as a surrogate for this outcome measure. ${ }^{24}$

HFCWO was first studied in an uncontrolled retrospective study demonstrating improved lung function after it was introduced. $^{25}$ Several short-term studies have suggested that HFCWO may be as effective as PD\&P. ${ }^{26-30}$ A recent study by Osman et $a l^{31}$ comparing HFCWO with participants' usual ACT found that significantly more sputum was produced with participants' usual ACT. Sontag et $a l^{32}$ recently published the results of a long-term study comparing HFCWO with PD\&P and Flutter. The study was discontinued early due to a high dropout rate in the PD\&P and Flutter groups. Although the study did suggest higher satisfaction rates with HFCWO, there was a significantly steeper decline in $\mathrm{FEF}_{25-75}$ in this group. Previous studies therefore do not provide strong support for the efficacy of HFCWO as the primary form of ACT, and this is supported by the findings of this trial. In our study $\mathrm{FEF}_{25-75}$ was trending downwards, but increased again between visit 5 (at 9 months) and visit 6 (at 12 months). When we examined this effect, we found that 30 of 46 subjects in the HFCWO group required antibiotics for a PE during this time. The increase may therefore have been a treatment effect of the antibiotics and warrants further investigation.

Reported adherence rates for both HFCWO and PEP, although of limited reliability, were well above the previously documented adherence rates of $51-74 \%$ in childhood, 50\% in adolescence and $30-32 \%$ in adulthood. ${ }^{33}$ Interest in participating in the study due to perceived effectiveness of a treatment may have led to improved adherence and treatment satisfaction. ${ }^{32}$ Close contact and telephone calls from study coordinators may also have contributed to increased adherence. The high adherence may explain the significant increase in percent predicted $\mathrm{FEV}_{1}$ and $\mathrm{FVC}$ in both groups from their baseline value.

Although a full cost analysis has not been performed, several cost factors need to be considered when deciding which ACT to use. First, the cost of a PEP mask is significantly less than a HFCWO device (approximately $£ 50$ and $£ 7000$, respectively). Second, in order to maintain health, the number of hospitalisations for PE in this study was three times more in the HFCWO group than in the PEP group (19 vs 6). The cost of hospitalisation is significant for our health economy and also causes a significant burden for the family of people with CF. Thus, at a time when we are looking to reduce health costs, unless there is strong evidence to support the use of more expensive equipment we cannot justify the cost.

\section{CONCLUSIONS}

The relatively lower PE rates and their later onset in patients performing PEP therapy compared with HFCWO supports the use of PEP as the primary ACT in patients with CF aged $>6$ years. This is the first long-term efficacy trial comparing HFCWO with any other ACT, and the results of this study do not support the use of HFCWO as the primary means of AC therapy in patients with CF. Additional evidence is needed to 
evaluate whether HFCWO combined with other forms of ACT is efficacious in these patients. Health costs also need to be a factor when considering which ACT to use.

\author{
Author affiliations \\ ${ }^{1}$ Division of Paediatric Respirology and Department of Physiotherapy, Cystic Fibrosis \\ Clinic, BC Children's Hospital and University of British Columbia, Vancouver, British \\ Columbia, Canada \\ ${ }^{2}$ Division of Pediatric Respiratory Medicine, Montreal Children's Hospital, Allied \\ Health Services, Physiotherapy Department, McGill University Health Center Research \\ Institute, Montreal, Quebec, Canada \\ ${ }^{3}$ Department of Paediatrics, Cystic Fibrosis, BC Children's Hospital and University of \\ British Columbia, Vancouver, British Columbia, Canada \\ ${ }^{4}$ Division of Pediatric Respiratory Medicine, Montreal Children's Hospital, McGill \\ University Health Center Research Institute, Montreal, Quebec, Canada \\ ${ }^{5}$ Division of Respiratory Medicine, Department of Pediatrics, and Program in \\ Physiology and Experimental Medicine, SickKids Research Institute, The Hospital for \\ Sick Children, and University of Toronto, Toronto, Ontario, Canada \\ ${ }^{6}$ Child and Family Research Institute, University of British Columbia, Vancouver, \\ British Columbia, Canada \\ ${ }^{7}$ Division of Respiratory Medicine, Department of Rehabilitation Services, The \\ Hospital for Sick Children, and University of Toronto, Toronto, Ontario, Canada \\ ${ }^{8}$ Division of Respiratory Medicine, Department of Rehabilitation Services, SickKids \\ Research Institute, The Hospital for Sick Children, and University of Toronto, Toronto, \\ Ontario, Canada
}

Acknowledgements The authors would like to thank the patients who participated in the study as well as the following Investigators and Research Coordinators from each of the participating Cystic Fibrosis Clinics: Mark Chilvers and Julie Fairbairn, BC Children's Hospital, Vancouver; Pierce Wilcox and Brigette Wilkins St Paul's Hospital, Vancouver; Candice Bjornson and Clare Smith, Alberta Children's Hospital, Calgary; Harvey Rabin and Clare Smith, Foothills Medical Centre, Calgary; Hans Pasterkamp and Linda Kraemer, Children's Hospital of Winnipeg, The Hospital for Sick Children, Toronto; Sherri Katz and Linda LaPointe, Children's Hospital of Eastern Ontario Ottawa; Shawn Aaron and Lynne Orser, Ottawa General Hospital; Mary Noseworthy, Palinder Kamra and Stephanie Spencer, Janeway Children's Health and Rehabilitation Centre, Newfoundland, Montreal Children's Hospital, Montreal; Jacques-Edouard Marcotte and Nadia Marquis, St Justine, Montreal; Patrick Daigneault and Christine Bouchard, Centre Mère-Enfant du CHUQ, Quebec City.

Contributors $M M C l, N A, G D, L C L, B O, F R, R M$ and JLA: literature search; $M M C l$, $\mathrm{BO}$ and JLA: data collection; MMcl, NA, RM, BO and JLA: data analysis; MMcl, NA, GD, LCL, FR, RM, BO and JLA: data interpretation; MMCl, NA, GD, LCL, BO, FR, RM and JLA: manuscript preparation, review and approval: all authors. MMcl is the guarantor of the study.

Funding The study was funded by a grant from the Canadian Cystic Fibrosis Foundation, now called Cystic Fibrosis Canada. RespirTech kindly loaned high frequency chest wall oscillator devices to each of the participants randomised to HFCWO. Smith Medical kindly provided TheraPEP devices and masks to each of the participants randomised to PEP. Neither company was involved in the study except for teaching use of their devices and neither provided any financial resources except for equipment for the study.

\section{Competing interests None.}

Ethics approval This was a multicentre study involving 12 sites. Ethics approval was obtained from the ethics board of each centre prior to any subjects being enrolled at that centre.

Provenance and peer review Not commissioned; internally peer reviewed.

\section{REFERENCES}

1 Boucher RC. New concepts of the pathogenesis of cystic fibrosis lung disease. Eur Respir J 2004;23:146-58.

2 Davis PB, Drumm M, Konstan MW. State of the art: cystic fibrosis. Am J Respir Crit Care Med 1996;154:1229-56.

3 Flume PA, Robinson KA, O'Sullivan BP, et al. Clinical practice guidelines for pulmonary therapies committee. Cystic fibrosis pulmonary guidelines: airway clearance therapies. Respir Care 2009;54:522-37.

4 Bott J, Blumenthal S, Buxton M, et al. Guidelines for the physiotherapy management of the adult, medical, spontaneously breathing patient. Thorax 2009;64:1-52

5 International Physiotherapy Group for Cystic Fibrosis. Physiotherapy in the treatment of cystic fibrosis. 4th edn. 2009. Cystic Fibrosis Worldwide. http://www.cfww.org (accessed January 29 2013).

6 Mcllwaine M, Agnew J, Black C. Use of airway clearance techniques in cystic fibrosis clinics in Canada [abstract]. Pediatr Pulmonol 2008;43(Suppl 31):P392.
7 Mcllwaine PM, Wong LTK, Peacock D, et al. Long-term comparative trial of conventional postural drainage and percussion versus positive expiratory pressure physiotherapy in the treatment of cystic fibrosis. J Pediatr 1997;131:570-4.

8 Gaskin L, Corey M, Shin J, et al. Long-term trial of conventional postural drainage and percussion versus positive expiratory pressure [abstract]. Pediatr Pulmonol 1998;26(Suppl 17):p345

9 Hansen LG, Warwick WJ, Hansen KL. Mucus transport mechanisms in relation to the effect of high frequency chest compression (HFCC) on mucus clearance. Pediatr Pulmonol 1994;17:113-18.

10 Dasgupta B, Brown NE, King M. Effects of sputum oscillations and rhDNase in vitro: a combined approach to treat cystic fibrosis lung disease. Pediatr Pulmonol 1998:26:250-5.

11 Morrison L, Agnew J. Oscillating devices for airway clearance in cystic fibrosis. Cochrane Cystic Fibrosis and Genetic Disorders Group. Cochrane Database Syst Rev 2009;(1):CD006842

12 Milla CE, Hansen LG, Weber A, et al. High-frequency chest compression: effect of the third generation compression waveform. Biomed Instrum Technol 2004;38:322-8.

13 Saiman L, Anstead M, Mayer-Hamblett N, et al. Effect of azithromycin on pulmonary function in patients with cystic fibrosis uninfected with Pseudomonas aeruginosa. A randomized controlled trial. JAMA 2010;303:1707-15.

14 Treggiari MM, Rosenfeld M, Mayer-Hamblett N, et al. EPIC Study Group. Early anti-pseudomonal acquisition in young patients with cystic fibrosis: rationale and design of the EPIC clinical trial and observational study. Contemp Clin Trials 2009;30:256-68

15 American Thoracic Society. Standardization of spirometry: 1994 update. Am J Respir Crit Care Med 1995;152;1107-36.

16 Stanojevic S, Wade A, Stocks J, et al. Reference ranges for spirometry across all ages. Am J Respir Crit Care Med 2008;177:253-60.

17 Quittner AL, Buu A, Messer MA, et al. Development and validation of the cystic fibrosis questionnaire in the United States: a health-related quality-of-life measure for cystic fibrosis. Chest 2005;128:2347-54.

18 Quittner AL, Buu A, Watrous M, et al. Cystic Fibrosis Questionnaire: A Health-Related Quality of Life Measure. User Manual English Version 2.0. The Cystic Fibrosis Foundation and Genentech, 2000.

19 Elkins MR, Robinson M, Rose BR, et al. A controlled trial of long-term inhaled hypertonic saline in patients with cystic fibrosis. N Engl J Med 2006:354:229-40.

20 Bendiak GN, Ratjen F. The approach to Pseudomonas aeruginosa in cystic fibrosis Semin Respir Crit Care Med 2009:30:587-95.

21 Fuchs HJ, Borowitz DS, Christiansen DH, et al. Effect of aerosolized recombinant human DNase on exacerbations of respiratory symptoms and pulmonary function in patients with cystic fibrosis. N Engl I Med 1994:331:637-42.

22 Quittner AL, Modi AC, Wainwright C, et al. Determination of the minimal clinically important difference scores for the cystic fibrosis questionnaire-revised respiratory symptom scale in two populations of patients with cystic fibrosis and chronic Pseudomonas aeruginosa airway infection. Chest 2009:135:1610-18.

23 Mayer-Hamblett N, Ramsey BW, Kronmal RA. Advancing outcome measures for the new era of drug development in cystic fibrosis. Am Thorac Soc 2007:4:370-7.

24 Waters V, Stanojevic S, Eshetu G, et al. Effect of pulmonary exacerbations on long-term lung function decline in cystic fibrosis. Eur Respir J 2012;40:61-6.

25 Warwick WE, Hansen LG. The long-term effect of high frequency chest compression therapy on pulmonary complications of cystic fibrosis. Pediatr Pulmonol 1991;11:265-71.

26 Arenas GD, Olin KJ, Vega J, et al. Comparison of high frequency chest compression and conventional chest physiotherapy in hospitalized patients with cystic fibrosis. Am J Respir Crit Care Med 1994;150:1154-7.

27 Braggion C, Appellate LM, Cornacchia M, et al. Short-term effects of three chest physiotherapy regimens in patients hospitalized for pulmonary exacerbations of cystic fibrosis: across-over randomized trial. Pediatr Pulmonol 1995;19:16-22.

28 Oermann CM, Sockrider MM, Giles D, et al. Comparison of high frequency chest wall oscillation and oscillating positive expiratory pressure in the home management of cystic fibrosis: a pilot study. Pediatr Pulmonol 2001:22:372-7.

29 Varekojiss SM, Douce FH, Flucke RL, et al. A comparison of the therapeutic effectiveness of and preference for postural drainage and percussion, intrapulmonary percussive ventilation, and high frequency chest wall compression in hospitalized cystic fibrosis patients. Respir Care 2003:48:24-8.

30 Phillips GE, Pike SE, Jaffe A, et al. Comparison of active cycle of breathing and high frequency oscillation jacket in children with cystic fibrosis. Pediatr Pulmonol 2004:37:71-5.

31 Osman LP, Roughton M, Hodson ME, et al. Short-term comparative study of high frequency chest wall oscillation and European airway clearance techniques in patients with cystic fibrosis. Thorax 2010;65:196-200.

32 Sontag MK, Quittner AL, Modi AC, et al. Lessons learned from a randomized trial of airway secretion clearance techniques in cystic fibrosis. Pediatr Pulmonol 2010:45:291-300.

33 Modi AC, Cassedy AE, Quittner AL, et al. Trajectories of adherence to airway clearance therapy for patients with cystic fibrosis. J Pediatr Psychol 2010;35:1028-37. 